\title{
CONTRIBUIÇÕES DO PIBID PARA A FORMAÇÃO INICIAL DOCENTE EM LICENCIATURA EM QUÍMICA: UM OLHAR ATENTO SOBRE OS FUTUROS PROFESSORES.
}

\author{
JaQueline de Lima Nascimento ${ }^{1}$, Marcus Vinícius Pinheiro Lopes ${ }^{1}$ \\ ${ }^{1}$ Instituto Federal de Educação, Ciência e Tecnologia do Ceará - IFCE \\ <jaquelinequimica96@gmail.com><marcus.lopes@ifce.edu.br> \\ DOI: <https://doi.org/10.21439/conexoes.v14i4.1487>
}

\begin{abstract}
Resumo. O Programa Institucional de Bolsa de Iniciação à Docência (PIBID) proporciona aos discentes de licenciatura o contato direto com o contexto escolar. Esse estudo almeja reconhecer, compreender e apresentar as contribuições do PIBID para a formação inicial docente dos estudantes de Licenciatura em Química. Objetiva-se de modo específico analisar os benefícios das relações entre bolsista-supervisor para o desenvolvimento do futuro docente; demonstrar a relevância da vivência de situações reais para a aquisição de conhecimentos práticos importantes para o enriquecimento da formação e ação pedagógica do bolsista e apontar as vantagens da sua proximidade com a carreira do magistério concedida pelo PIBID. Foi utilizada a abordagem quantitativa com o estudo de caso. Foram elaborados dois (2) questionários: um para o bolsista do PIBID e outro para o supervisor. Participaram trinta (30) bolsistas e três (3) supervisores e suas respostas foram analisadas. Esse programa possibilita aos discentes experiências que enriquecem sua formação enquanto docente proporcionando um contato inicial com sua profissão. O contato com os bolsistas favorece aos supervisores o compartilhamento de vivências e conhecimentos motivando-os a buscar novas informações e práticas metodológicas, além do incentivo para dar continuidade em sua formação acadêmica.
\end{abstract}

Palavras-chaves: Contribuições do PIBID. Formação inicial docente. Discentes de Licenciatura em Química.

\begin{abstract}
The Institutional Scholarship Initiative Program (PIBID) provides undergraduate students with direct contact with the school context. This study aims to recognize, understand and present the contributions of PIBID to the initial teacher education of undergraduate students in Chemistry. Specifically, it aims to analyze the benefits of the relations between scholarship-supervisor for the development of the future teacher; to demonstrate the relevance of the experience of real situations to the acquisition of practical knowledge important for the enrichment of the training and pedagogical action of the scholarship holder and to point out the advantages of its proximity to the teaching career granted by PIBID. The quantitative approach was used with the case study. Two (2) questionnaires were prepared: one for PIBID grantees and one for supervisor. Thirty (30) fellows and three (3) supervisors participated and their answers were analyzed. This program gives students experiences that enrich their training as a teacher providing an initial contact to their profession. The contact with the scholarship recipients favors the supervisors the sharing of experiences and knowledge motivating them to seek new information and methodological practices, besides the incentive to continue in their academic formation.
\end{abstract}

Keywords: PIBID contributions. Initial teacher training. Students of Degree in Chemistry. 


\section{INTRODUÇÃO}

A formação de professores é um assunto importante e que gera inúmeras discussões a seu respeito por se tratar de uma profissão que possui um papel significativo na sociedade. Os professores podem contribuir para a formação de indivíduos críticos e reflexivos e dessa forma podem ser importantes ferramentas para a construção de uma sociedade mais justa e ciente dos problemas enfrentados pelo seu povo.

A formação docente se dá em ensino superior e é regulamentada por lei. No entanto, a formação de professores é permanente tendo início designado de formação inicial em que os educadores passam a percorrer um longo caminho. Esse profissional deve sempre estar se atualizando e também se renovando buscando novas ações, conceitos e teorias objetivando melhorias na sua prática docente (BACCON; BRANDT; WOLSKI 2013).

O Programa Institucional de Bolsa de Iniciação à Docência (PIBID) foi instituído no ano de 2007 pela Coordenação de Aperfeiçoamento de Pessoal de Nível Superior (CAPES) que financia esse programa que tem como finalidade articular a educação básica com a formação inicial docente (TOBALDINI, 2012).

Esse programa é composto por discentes e docentes de todo o território nacional. O mesmo visa o aperfeiçoamento e a valorização da formação de docentes para educação básica na qual concede bolsas a alunos de cursos de licenciatura que participam de projetos de iniciação à docência desenvolvidos por IES juntamente com escolas públicas da educação básica (BRASIL, 2017).

Segundo Zeulli et al. (2012), o PIBID é um programa importante por proporcionar aos futuros docentes experiências de sala de aula antes mesmo de terminarem seu curso superior. Dessa forma, de acordo Dick, Diesel e Horn (2015) ao se inserir os licenciandos em experiências práticas ainda durante a formação, ou seja, ainda estão sendo apresentados e adquiridos por eles vários conhecimentos de caráter teórico, por exemplo, está se permitindo a vivência de inúmeras situações e consequentemente, o ganho de novas aprendizagens por meio delas.

Silva et al. (2014) destaca que o PIBID vem assumindo papel de grande relevância no país em se tratando de formação inicial docente, atuando como uma proposta de incentivo e valorização do magistério na qual o licenciando entra em contato desde o início da sua formação acadêmica com metodologias de caráter inovador.

Conforme Sousa, Afonso e Sá (2015), a utilização de práticas pedagógicas inovadoras como, por exemplo, experimentos, jogos pedagógicos e teatro juntamente com as ações docentes habituais, colaboram para uma melhor compreensão dos conteúdos explorados nas aulas auxiliando na diminuição da abstração dos mesmos.

Segundo Mattana et al. (2014), as atividades desempenhadas pelos bolsistas auxiliam na formação inicial desses discentes através da discussão de concepções sobre ensino e aprendizagem inovadoras para os alunos da educação básica considerando a escola como espaço propício para praticar tais ações. O programa PIBID ainda auxilia como instrumento de reflexão colaborando com os bolsistas no que diz respeito à sua prática pedagógica e também na busca de aperfeiçoar ações que facilitem o processo de ensino-aprendizagem.

O programa em questão também contribui para a formação continuada dos professores através das trocas de experiências entre os supervisores, coordenadores e os bolsistas; na reflexão da sua própria prática docente e também na reflexão e discussão no que diz respeito ao estudo da teoria e a sua aplicabilidade em sala de aula (JARDILINO; OLIVERI, 2013).

Martins, Neta e Leite (2012) afirmam que as situações, ações e experiências promovidas pelo PIBID colaboram para a atualização e renovação dos conhecimentos e prática docente dos professores que são supervisores desse programa nas escolas conveniadas acarretando alterações na ação pedagógica por meio da participação desses profissionais nas atividades promovidas pelo PIBID na escola.

Além do mais, o PIBID possibilita as escolas parceiras a esse programa novas experiências em se tratando de aprendizagem, na qual o aluno percebe a sua importância nesse processo. Quanto às mudanças nas atitudes dos alunos, perceberam-se a melhora do comportamento, da concentração e também na relação com o docente (ROSA; MATTOS, 2013).

Diante desse contexto, o presente estudo tem como objetivo reconhecer, compreender e apresentar as contribuições do PIBID para a formação inicial docente dos licenciandos em Química. Para o alcance desse propósito pretende-se de modo específico analisar os benefícios das relações estabelecidas entre bolsista-supervisor para a formação do futuro docente; demonstrar a relevância da vivência de situações reais para a aquisição de conhecimentos práticos importantes para o enriquecimento tanto da formação do licenciando quanto de sua ação pedagógica; apontar, ainda, as vantagens da proximidade entre licenciando com a sua futura área profissional concedida pelo PIBID. Esse reconhecimento da importância do programa para os estudantes e para a sociedade é primordial para que sempre ocorra a ma- 
nutenção destes modelos de projetos por governos em suas diferentes escalas.

\section{METODOLOGIA}

\subsection{Público-alvo}

Participaram desta pesquisa trinta (30) bolsistas do PIBID do subprojeto Química de uma Instituição de Ensino Superior (IES) da cidade de Quixadá-CE, sendo que esses bolsistas são regulamente matriculados no curso de Licenciatura em Química dessa mesma instituição, pertencentes a diferentes semestres desse curso. Participaram também três (3) supervisores desse mesmo subprojeto que são professores que constituem o corpo docente de três (3) escolas de ensino médio da rede pública situadas também na cidade de Quixadá-CE na qual atua o PIBID. Esses bolsistas são na maioria jovens e que estão fazendo parte do referido programa a menos de um (1) ano. Em relação aos supervisores, estes são professores efetivos de escolas da rede estadual de ensino e já atuam no PIBID nessa função há mais de dois (2) anos, ou seja, já possuem certa experiência no programa mencionado.

\subsection{Procedimentos}

Nessa pesquisa foi realizado um estudo de caso e a análise dos dados obtidos foi feita de forma quantitativa com auxílio de alguns comentários textuais dos entrevistados. Segundo Gil (2009) um estudo de caso deve examinar uma fonte rica e estável de dados, não existindo contato com os indivíduos da pesquisa, além de haver um estudo profundo de um ou mais objetos, onde os limites estão claramente definidos. Para o levantamento dos dados pertinentes foram disponibilizados dois (2) questionários: um voltado para os bolsistas do PIBID e outro para os supervisores desse programa contendo tanto questões objetivas quanto subjetivas. Estes foram disponibilizados na sua forma impressa e também online por meio de um formulário eletrônico.

Antes da aplicação desses questionários, foi previamente esclarecido aos participantes que a sua identificação não era necessária ao responder o mesmo garantindo assim o total sigilo de sua identidade. Os participantes também não foram influenciados e/ou induzidos a responder algo.

O questionário voltado para os bolsistas foi aplicado para um quantitativo de trinta (30) discentes contendo questões referentes às suas experiências no PIBID e as contribuições para a sua formação como futuro professor. Desse total de bolsistas, vinte e quatro (24) responderam ao questionário no seu formato impresso e seis (6) bolsistas responderam ao mesmo via formulário eletrônico ou e-mail.

Três (3) professores/supervisores do PIBID que trabalham em três (3) escolas da educação básica diferentes, que são parceiras desse programa, responderam ao questionário voltado para os mesmos contendo questões que tratavam sobre as experiências como supervisor, as contribuições do PIBID para sua formação, os benefícios para os alunos que recebem o acompanhamento dos bolsistas e por fim, as implicações desse programa para os licenciandos/bolsistas. Todos esses supervisores responderam o questionário online.

Em seguida os dados foram concatenados na forma de Gráficos e Tabelas que serão mostrados e discutidos a seguir.

\section{RESULTADOS E DISCUSSÃO}

\subsection{Análise dos dados obtidos através do questio- nário voltado para os bolsistas}

Neste primeiro momento serão discutidas informações obtidas no questionário aplicado aos bolsistas (estudantes) participantes do PIBID. Na Figura 1 são mostrados os dados sobre se o PIBID promove ao bolsista o confronto entre a teoria e a prática dos conhecimentos adquiridos no decorrer de sua formação como docente. Dos entrevistados, $83 \%$ mencionaram que essa situação sempre ocorre e os outros $17 \%$ alegaram que frequentemente.

Figura 1: Se o PIBID proporciona ao bolsista o confronto entre a teoria e a prática dos conhecimentos adquiridos em sua formação acadêmica.

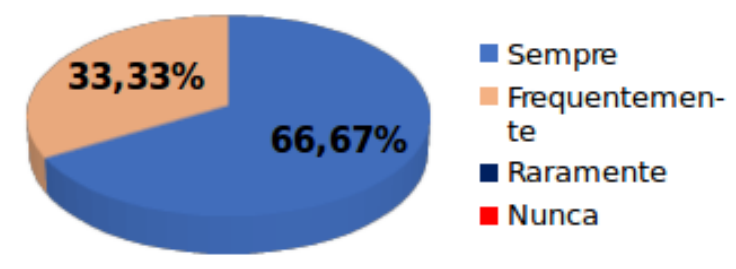

O PIBID ao inserir o licenciando no contexto escolar está possibilitando ao mesmo o convívio com situações reais e comumente vivenciadas nas escolas e desta maneira, possibilita ao discente relacionar os conhecimentos adquiridos em sua formação com os conhecimentos proporcionados pela experiência, ou seja, o possível confronto entre a teoria e a prática dos co- 
nhecimentos. Assim, estes indivíduos podem formar as suas próprias conclusões sobre as situações práticas vivenciadas e verificar se as mesmas concordam ou não com que é posto em teoria. Vale ressaltar também que cada profissional docente tem a livre escolha de investigar qual e melhor prática docente a se ser utilizada em sala de aula.

O programa em estudo ainda possibilita aos discentes de licenciatura entrar em contato com a realidade escolar ainda estando em plena formação, ou seja, enquanto eles ainda estão estudando a teoria no ambiente acadêmico. Sendo assim, não é possível a segregação entre teoria e prática, visto que ambas formam um conjunto fundamental para que o docente como profissional desempenhe suas ações (BERTOLDO; CHIAPINOTO 2014).

A Figura 2 retrata que $67 \%$ dos bolsistas responderam que as atividades desenvolvidas no âmbito do PIBID sempre contribuem para que eles correlacionem as disciplinas específicas com as pedagógicas do seu curso. Os demais, $33 \%$ relataram que frequentemente essa situação ocorre.

Figura 2: Se as ações desenvolvidas pelos bolsistas permitem que eles correlacionem as disciplinas específicas com as pedagógicas do seu curso.

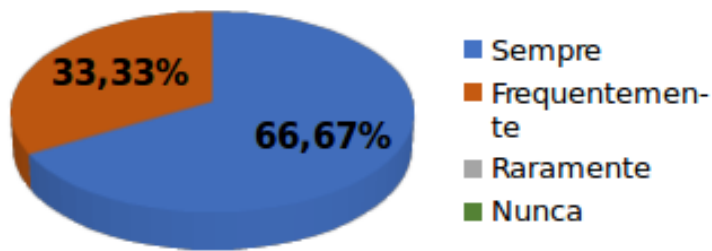

Essa correlação entre os conhecimentos específicos e pedagógicos enfatiza que, seja em uma preparação de um experimento, oficina pedagógica ou em um jogo lúdico, estes devem estar vinculados para que os objetivos da utilização dessas ações sejam alcançados com a aprendizagem efetiva dos estudantes.

Ao vivenciar o contexto escolar e as ações pedagógicas em sua área de formação, o licenciando perceberá que o espaço da sala de aula é onde o conhecimento se converte em práticas docentes (NEITZEL; FERREIRA; COSTA, 2013). Em outras palavras, em sala de aula o bolsista terá que relacionar seus conhecimentos já adquiridos em sua formação (ainda em andamento) para formular suas práticas pedagógicas e estratégias educa- cionais de forma a proporcionar um ensino de qualidade e consequentemente a aprendizagem dos estudantes.

Na Figura 3 é mostrada a opinião dos bolsistas sobre a alteração em sua perspectiva quanto à docência e ao contexto escolar com a sua atuação no PIBID. Dos entrevistados, $70 \%$ responderam que sempre ocorre essa alteração e 30

Figura 3: Modificação na perspectiva dos bolsistas quanto à docência e ao contexto escolar.

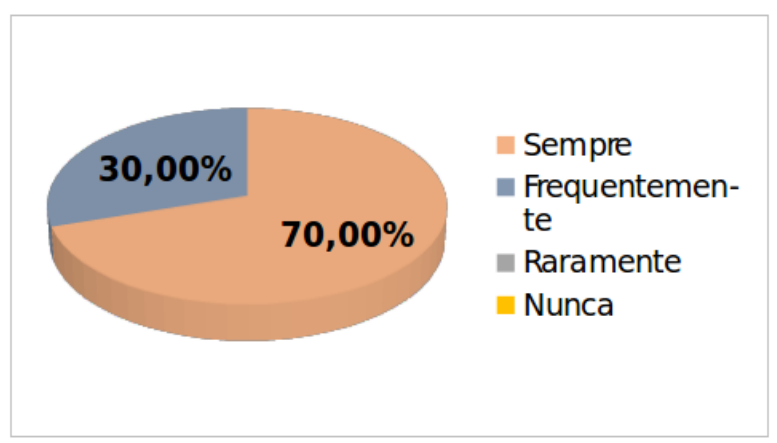

A inserção desses bolsistas do PIBID na realidade escolar faz com que eles entrem em contato com as experiências e situações próprias desse contexto e da sua futura profissão. No entanto, eles retornam para esse âmbito em outro papel, não mais como aluno mas agora como docente. Por conseguinte, passam a ver os discentes, professores e a escola como um todo sob uma nova perspectiva, alterando na maioria das vezes sua visão quanto a esse cenário e seus constituintes. Dessa forma, como mostrado na Figura 3 podemos comprovar essa mudança de perspectiva junto ao corpo de alunos da pesquisa, em sua maioria $(70 \%)$.

As ações realizadas pelos bolsistas propiciam-lhes uma mudança de visão sobre o âmbito escolar e a formação de professores, além de ocasionar alterações em relação a argumentos e opiniões a respeito da profissão docente (PERETTO et al. 2015). Logo, eles passam a compreender melhor o papel do professor visto que irão vivenciar as experiências da profissão em questão, ocasionando alterações em seu ponto de vista quanto à docência, sua importante função na sociedade e as diversas circunstâncias que permeiam o cotidiano desse profissional.

$\mathrm{Na}$ Tabela 1 são apresentados alguns dos relatos fornecidos pelos licenciandos sobre a contribuição do PIBID na sua formação inicial enquanto futuro docente.

Com bases nos relatos, o PIBID proporciona aos mesmos um contato que os aproximam das situações reais do cotidiano das escolas da educação básica preparando-os para a sua futura atuação na profissão. 
Tabela 1: Respostas dos bolsistas sobre a contribuição do PIBID na sua formação inicial como futuro docente.

\begin{tabular}{|c|l|}
\hline Aluno & \multicolumn{1}{c|}{ Resposta } \\
\hline Bolsista 19 & $\begin{array}{l}\text { "O PIBID proporciona ao bolsista chegar mais perto da realidade do ensino-aprendizagem na } \\
\text { escola pública. As atividades que realizamos cada vez mais nos deixam tranquilos diante da } \\
\text { classe. Como acadêmicos, nos levam a buscar mais o conhecimento químico". }\end{array}$ \\
\hline Bolsista 20 & $\begin{array}{l}\text { "Esse programa nos dá uma primordial orientação, principalmente para os graduandos que } \\
\text { nunca tiveram contato com a sala de aula. Proporciona-nos novas metodologias de ensino que } \\
\text { ampliam o campo de visão para o ensino médio". }\end{array}$ \\
\hline Bolsista 22 & $\begin{array}{l}\text { "Ao colocar em prática a profissão docente, nós como futuros professores, temos acesso à } \\
\text { realidade vivenciada e podemos definir se é essa a profissão que pretendemos seguir". }\end{array}$ \\
\hline Bolsista 23 & $\begin{array}{l}\text { "Ajudou-me a ter uma visão diferente, de forma que agora enxergo o conteúdo ministrado } \\
\text { sob a ótica do aluno". }\end{array}$ \\
\hline Bolsista 24 & $\begin{array}{l}\text { "O PIBID nos permite a vivência na sala de aula, nos dando experiência para quando formos } \\
\text { atuar como professores sabermos lidar com algumas situações". }\end{array}$ \\
\hline Bolsista 29 29 & $\begin{array}{l}\text { "O PIBID proporciona para gente a relação entre teoria e prática, deixando-nos preparados } \\
\text { para o nosso futuro como professores". }\end{array}$ \\
\hline
\end{tabular}

Gama et al. (2013) reforça a ideia anterior, onde cita que o PIBID possibilita o amadurecimento e a evolução do bolsista no âmbito da docência, contribuindo diretamente em sua formação ainda em andamento, qualificando-o melhor para sua futura área profissional.

O licenciando/bolsista por meio do PIBID, conhece e compreende de forma mais aprofundada a sala de aula e também lhe proporciona articular a teoria vista na universidade com a prática presente no contexto escolar (MARQUES; CORDEIRO; TAVARES, 2015). Esse convívio também possibilita aos mesmos voltarem o seu olhar de forma mais atenta em relação a sua prática docente, pois inseridos no seu futuro ambiente de trabalho, estes observarão, agora com olhos de docentes, a questão do educando e a sua aprendizagem tendo uma maior entendimento sobre sua futura profissão.

Felício (2014) também relata sobre essa modificação na visão dos licenciandos em relação à profissão docente, afirmando que através das vivências possibilitadas pelo PIBID, o pensamento desses bolsistas vai se distanciando da concepção que a docência se resume simplesmente na transmissão de conhecimentos. Ou seja, esses discentes ao conviver com a realidade escolar vão compreendendo cada vez mais a sua futura área de atuação profissional.

No que se refere à opinião dos bolsistas sobre o que eles consideram como o principal diferencial de um discente de licenciatura que foi bolsista do PIBID ao contrapor com os licenciandos que não participaram desse programa, na Tabela 2 são mostradas algumas das respostas dadas a referida questão.

De acordo com as ideias apresentadas, uma das várias implicações do PIBID para a formação dos licen- ciandos/bolsistas diz respeito ao mercado de trabalho, pois ao concluir a graduação, o ex-bolsista do PIBID conhecerá melhor a profissão além de sair preparado para exercê-la. Com essa experiência prévia a maioria das situações que envolvem a carreira docente já foi vivenciada por conta das experiências proporcionadas enquanto bolsista de um programa de iniciação à docência em comparação com aquele que não participou de um programa semelhante que possibilitasse essas práticas.

O convívio com as escolas parceiras ao PIBID possibilita ao licenciando desenvolver habilidades de forma a enfrentar da melhor maneira determinadas circunstâncias presentes no cotidiano escolar. Sem essa oportunidade de vivenciá-las, ainda em formação, na maioria das vezes, o mesmo só irá passar por essa mesma experiência já atuando na profissão no mercado de trabalho, ou seja, após a conclusão do seu curso (HERBER; FILHO; PINO, 2016).

Sobre o que deve ser aperfeiçoado no PIBID, na Tabela 3 são mostradas algumas das opiniões dos bolsistas desse programa referente a essa questão.

De acordo com as opiniões apresentadas na Tabela 3 se pode investir ainda mais nesse programa, pois como é voltado para a formação inicial docente, esse investimento no magistério afetará diretamente as escolas, interferindo positivamente na qualidade da educação.

De maneira geral, o PIBID não é apenas um programa que disponibiliza bolsas, mas que atua na valorização da profissão docente e também no aprimoramento da formação de professores. Além do mais, possibilita inúmeras trocas de conhecimentos entre IES e as escolas da educação básica (SILVA, 2016). Além disso, 
Tabela 2: Respostas dos licenciandos sobre o que eles consideram como o principal diferencial de um estudante que foi bolsista do PIBID em comparação a um discente que não foi bolsista desse programa.

\begin{tabular}{|c|l|}
\hline Aluno & \multicolumn{1}{c|}{ Resposta } \\
\hline Bolsista 9 & $\begin{array}{l}\text { "Torna-se mais preparado para superar as dificuldades que o professor recém-formado encontra } \\
\text { ao ingressar no ambiente escolar". }\end{array}$ \\
\hline Bolsista 14 & $\begin{array}{l}\text { "A convivência com a realidade das escolas proporciona ao aluno participante do programa } \\
\text { maior experiência em lidar com os alunos e de como ministrar os conteúdos didaticamente". }\end{array}$ \\
\hline Bolsista 18 & $\begin{array}{l}\text { "O aluno que participou do programa tem mais experiência com uma sala de aula e já tem um } \\
\text { pouco de conhecimento para ser um professor diferenciado, com aulas dinâmicas e várias } \\
\text { estratégias para obter a atenção do aluno". }\end{array}$ \\
\hline Bolsista 19 & $\begin{array}{l}\text { "Devido à prática exercida, o bolsista tem mais facilidade para liderar uma turma já que muitas } \\
\text { dificuldades já foram enfrentadas. O bolsista não terá muito problema para lidar com o novo". }\end{array}$ \\
\hline Bolsista 21 & $\begin{array}{l}\text { "Com o programa temos contato com a escola logo no início do curso o que ajuda a nos } \\
\text { preparar para a docência". }\end{array}$ \\
\hline Bolsista 29 & $\begin{array}{l}\text { "Principalmente a didática e também por já estarmos dentro da escola sabemos a realidade, } \\
\text { o que nos faz ter experiência na sala de aula". }\end{array}$ \\
\hline
\end{tabular}

Tabela 3: Respostas dos licenciandos sobre o que deve ser aperfeiçoado no PIBID.

\begin{tabular}{|c|l|}
\hline \multicolumn{1}{|c|}{ Aluno } & \multicolumn{1}{c|}{ Resposta } \\
\hline Bolsista 12 & $\begin{array}{l}\text { "Assim como outros programas o PIBID também precisa melhorar, mais o necessário } \\
\text { não é um aperfeiçoamento do programa, mais sim um reconhecimento daqueles que são } \\
\text { externos ao mesmo". }\end{array}$ \\
\hline Bolsista 13 & $\begin{array}{l}\text { "A realização de projetos promovidos pelos bolsistas que trabalhem temas voltados para a } \\
\text { realidade dos estudantes". }\end{array}$ \\
\hline Bolsista 14 & $\begin{array}{l}\text { "Maior abrangência por parte do projeto. O programa deve dar oportunidade a vários alunos do } \\
\text { curso de ter essa experiência em sala". }\end{array}$ \\
\hline Bolsista 19 & $\begin{array}{l}\text { "Os bolsistas têm que ser treinados para a liderança. Deveriam ser sempre avaliados de acordo } \\
\text { com seus feitos para não dar lugar à improdutividade ou comodismo". }\end{array}$ \\
\hline Bolsista 26 & "Investimento". \\
\hline Bolsista 29 & $\begin{array}{l}\text { "Não acho que deva se aperfeiçoar, acho que devemos seguir as regras tendo em vista que o } \\
\text { programa já é perfeito". }\end{array}$ \\
\hline
\end{tabular}

outro fator apontado para o aperfeiçoamento do PIBID seria o desenvolvimento de projetos com foco em assuntos que vão além dos conteúdos abordados em sala como, por exemplo, sobre a atualidade. No entanto, há opiniões que expressem que o PIBID não precisa se aperfeiçoar, que apresenta bons objetivos e que na prática soma inúmeras contribuições para a área da docência.

É pertinente relatar que o aumento do investimento no programa resultará em um maior número de bolsas abrangendo assim um quantitativo mais significativo de discentes de cursos de licenciaturas possibilitando a estes vivenciar experiências únicas geradas pela interação antecipada com o ambiente escolar ainda no início de sua formação profissional.

\subsection{Análise dos dados obtidos através do questio- nário voltado para os supervisores}

Nesse segundo momento serão discutidas as informações obtidas no questionário aplicado aos supervisores do PIBID. Na Tabela 4 são mostradas as sugestões de ações que podem ser promovidas pelos bolsistas do programa na perspectiva dos supervisores.

Dentre as sugestões dadas pelos professores/supervisores, a mais citada foi a referente às aulas de reforço e preparação para vestibulares e ENEM. Por mais que nas próprias aulas seja dada uma atenção especial a essa questão da preparação para os vestibulares e ENEM, seria interessante também desenvolver atividades de forma a complementar essa preparação seja através de simulados, gincanas, aulas em que possam se debater questões de provas dos anos anteriores, enfim, utilizando diversos recursos que 
Tabela 4: Sugestões de atividades que os bolsistas poderiam desempenhar nas escolas conveniadas.

\begin{tabular}{|c|l|}
\hline Professor & \multicolumn{1}{c|}{ Resposta } \\
\hline Supervisor 1 & $\begin{array}{l}\text { "Disponibilizar um horário para o reforço escolar; interagir mais com os alunos com atividades } \\
\text { diversificadas". }\end{array}$ \\
\hline Supervisor 2 & $\begin{array}{l}\text { "Poderiam ser desenvolvidas atividades de reforço, tipo aulões pré-vestibular/ENEM, porque } \\
\text { só em sala de aula fica pouco, e como nosso aluno gosta de estar na escola no contra turno isso } \\
\text { se torna algo mais construtivo para o futuro desse aluno". }\end{array}$ \\
\hline Supervisor 3 & $\begin{array}{l}\text { "Reforço escolar; realização de oficinas; confecção de jogos didáticos para serem utilizados } \\
\text { nas aulas; realização de gincanas e a produção de esquete teatral abordando os conteúdos } \\
\text { de Química". }\end{array}$ \\
\hline
\end{tabular}

estimulam esses estudantes a buscarem bons resultados em seus objetivos.

Também foram mencionados que os bolsistas poderiam desenvolver ações que trabalhem com o lúdico, oficinas, teatros dentre outras atividades apontadas, que abordam os conteúdos de maneira mais atrativa e que despertam o interesse dos alunos em participar de sua realização. Trabalhar com esses recursos mais atrativos não significa se afastar da preparação para o ENEM de tal forma que as atividades citadas anteriormente são voltadas para um maior entendimento dos assuntos abordados o que leva a uma preparação melhor dos estudantes em termos de conteúdos. Santos et al. (2011) acrescentam a essa ideia que a utilização de recursos pedagógicos diferenciados favorece a aprendizagem dos educandos por eles terem um papel ativo na construção do conhecimento, estando a sua disposição outros materiais além do livro didático.

$\mathrm{Na}$ Tabela 5] são apresentadas as respostas dos supervisores em relação à alteração/influência em suas metodologias utilizadas nas aulas por meio do contato com os bolsistas do PIBID.

Com base no que foi relatado na Tabela 5, o contato promovido pelo PIBID entre os supervisores e os licenciandos favorece além da troca de experiências entre ambos, o enriquecimento da formação docente desses professores por meio do contato com novas ideias de ações metodológicas.

$\mathrm{O}$ incentivo à pesquisa e à leitura de artigos científicos para o uso de informações nas aulas, a utilização de jogos pedagógicos, oficinas, ou seja, o uso de outros recursos pedagógicos com o intuito de melhorar as aulas pode ser estimulado por meio desse contato e, além disso, o convívio com esses discentes favorece também a aquisição de conhecimentos por conta desse estímulo e na busca de novas informações, dentro de sua área de conhecimento e principalmente ligadas à prática docente, contribuindo para a atualização dos conhecimentos desses profissionais em serviço.
Essa mesma situação também foi observada em um estudo realizado por Martins, Neta e Leite (2012). Esses autores ao questionarem os supervisores sobre as contribuições das ações promovidas pelo PIBID obtiveram as respostas de que essas atividades possibilitaram a atualização dos seus conhecimentos e também de sua prática docente, colaborando em seu crescimento profissional.

Em relação à existência de trocas de conhecimentos e experiências sobre a prática pedagógica entre supervisores e os bolsistas do PIBID, todas as respostas dos supervisores declararam que sempre ocorre esse tipo de experiência entre bolsistas e supervisores.

Essas circunstâncias possibilitam aos bolsistas compartilharem seus conhecimentos acadêmicos e novas informações adquiridas em sua formação ainda em andamento com os professores/supervisores contribuindo para a sua formação e renovação dos seus conhecimentos já existentes. Em contrapartida, os supervisores podem compartilhar além de conhecimentos, as suas vivências adquiridas com o exercício da sua profissão enriquecendo ainda mais a formação desses futuros docentes. Ou seja, esse convívio oportuniza significativos benefícios para a formação de ambos os envolvidos, possibilitando aquisição de novos saberes de suma importância para o exercício da profissão em questão como por exemplo ministrar uma aula contextualizada com a realidade dos alunos fazendo uso de um experimento de baixo custo que possa inclusive ser replicado em casa pelos próprios estudantes.

Sopelsa, Baldissera e Mello (2016) apontam que essas conversas e trocas referentes aos saberes docentes contribuem positivamente para a prática pedagógica dos envolvidos e, consequentemente, beneficia tanto o ensino quanto a aprendizagem dos discentes da educação básica.

Em um estudo desenvolvido por (MATOS, 2016), uma professora/supervisora relata sobre a importância dos compartilhamentos de experiências proporcionados 
Tabela 5: Respostas dos supervisores sobre a alteração/influência no que se refere às metodologias utilizadas em sala de aula após o contato com os bolsistas do PIBID e suas ações desempenhadas na escola.

\begin{tabular}{|c|l|}
\hline Professor & \multicolumn{1}{c|}{ Resposta } \\
\hline Supervisor 1 & $\begin{array}{l}\text { "Incentivo à leitura de artigos científicos para incrementar com novas informações as } \\
\text { minhas aulas". }\end{array}$ \\
\hline Supervisor 2 & $\begin{array}{l}\text { "Na elaboração dos slides, observei que tinha um bolsista que apresentava uma maneira } \\
\text { bem atrativa na apresentação de slide, jogando sempre os fenômenos observados como } \\
\text { perguntas geradoras para iniciar um conteúdo, vi que esse modo instigava a curiosidade } \\
\text { do aluno e comecei a trabalhar assim". }\end{array}$ \\
\hline Supervisor 3 & $\begin{array}{l}\text { "Minha atuação não mudou muito, mas a presença dos bolsistas nas turmas facilita a } \\
\text { aplicação das metodologias. As atividades em laboratório e aplicação de jogos didáticos } \\
\text { tornam-se mais fáceis de serem executadas com a contribuição e ajuda dos bolsistas". }\end{array}$ \\
\hline
\end{tabular}

pelo PIBID, sendo que muitas vezes se tem a concepção errônea que os licenciandos irão somente absorver os saberes propiciados pelos supervisores. No entanto, os professores supervisores também adquirem novos conhecimentos, como a introdução de metodologias diversificadas e atualização de conteúdos oriundos da universidade, atualizando-se dentro de sua área de atuação para sua formação profissional a partir dessa relação benéfica para ambos envolvidos.

Na Figura 4 são mostradas as informações sobre a influência dos bolsistas na motivação dos supervisores na busca por conhecimentos e ações metodológicas no intuito de tornar o ensino mais atrativo. Como se pode observar, $67 \%$ dos supervisores disseram que o contato com os bolsistas e suas respectivas ações sempre influenciam na sua motivação, sentindo-se mais estimulados e os outros $33 \%$ relataram que frequentemente ocorre essa interferência em sua motivação.

Figura 4: Se os supervisores se sentem mais motivados para buscar novos conhecimentos e metodologias para tornar as suas aulas mais atrativas e dinâmicas.

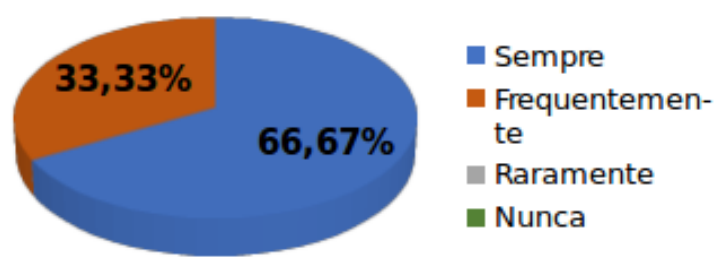

As conversas e os compartilhamentos de conhecimentos e experiências entre os bolsistas e seus supervisores podem atuar como um estímulo a esses docentes, motivando-os no que se refere à busca e à pesquisa de informações, renovando seus conhecimentos já adquiridos e suas metodologias utilizadas em sala de aula, interferindo em sua prática docente. Além disso, esse convívio estabelecido pelo PIBID entre esses indivíduos também contribui no desenvolvimento e execução de novas ideias por parte desses professores, atuando na melhoria do ensino e da aprendizagem dos alunos das escolas conveniadas.

Matos (2016) confirma essas palavras ao mencionar que a relação existente entre bolsistas e supervisores influencia na renovação da prática pedagógica, na motivação ao exercer o seu trabalho e na confiança do profissional da educação.

Na Tabela 6 estão dispostos os relatos dos supervisores descrevendo as contribuições do PIBID para a sua formação continuada enquanto docente.

Com base nessas declarações, percebe-se que os benefícios proporcionados pela relação entre supervisores e bolsistas vão além do enriquecimento da prática docente e de ações metodológicas. É notório nos relatos anteriores, o apoio e a motivação presentes nesse contato para que esses professores possam dar continuidade em sua formação através da sua participação em palestras, cursos e até mesmo no ingresso em uma pós-graduação.

Além disso, os licenciandos fornecem informações sobre concursos e seleção para mestrado, trocando informações e dicas de preparação para essas provas, incentivando-os a participar. Ou seja, os bolsistas ajudam os supervisores a estarem atualizados quanto à essas informações que por muitas vezes passam despercebidas por conta das atividades no cotidiano da sua profissão.

$\mathrm{Na}$ Tabela 7 se encontram sugestões do que deve ser aperfeiçoado no PIBID do ponto de vista dos professores/supervisores.

Com base nas respostas prestadas pelos superviso- 
Tabela 6: As contribuições do PIBID para a formação continuada dos professores/supervisores do referido programa.

\begin{tabular}{|c|l|}
\hline Professor & \multicolumn{1}{c|}{ Resposta } \\
\hline Supervisor 1 & "Incentiva a fazer um mestrado e a leitura de artigos científicos". \\
\hline Supervisor 2 & $\begin{array}{l}\text { "Como estamos fora do meio acadêmico, o bolsista nos deixa 'inteirado' das novidades } \\
\text { superiores, como palestras, eventos e até provas de seleções como de mestrado e concurso. } \\
\text { Sempre me sinto estimulada a participar por ter esse apoio por parte deles". }\end{array}$ \\
\hline Supervisor 3 & $\begin{array}{l}\text { "O contato com os bolsistas e as conversas com eles me estimulam a ingressar em uma } \\
\text { pós-graduação e que eu continue aperfeiçoando os meus conhecimentos, dando continuidade } \\
\text { a minha formação, além de dicas para uma melhor preparação para as provas dessas seleções". }\end{array}$ \\
\hline
\end{tabular}

Tabela 7: Respostas dos supervisores sobre o que deve ser aperfeiçoado no PIBID.

\begin{tabular}{|c|l|}
\hline Professor & \multicolumn{1}{c|}{ Resposta } \\
\hline Supervisor 1 & "Uma maior interação entre a instituição em questão e a escola". \\
\hline "Cada dia é um novo ensinamento, nova aprendizagem, que podemos melhorar com relação ao \\
Supervisor 2 & $\begin{array}{l}\text { tempo de dedicação e planejar mais coletivo (bolsista e supervisor). Porque na maioria dos } \\
\text { casos, o contato é mais no momento da aula, e não temos tempo para discutir novas formas de } \\
\text { ensino-aprendizagem". }\end{array}$ \\
\hline Supervisor 3 & $\begin{array}{l}\text { "O número de horas do bolsista na escola poderia ser ampliado; seria essencial a participação } \\
\text { do bolsista no dia do planejamento do professor e firmar uma parceria entre escola e } \\
\text { universidade para que esses alunos pudessem estar fazendo visitas periódicas } \\
\text { nas universidades". }\end{array}$ \\
\hline
\end{tabular}

res, prevalece nas declarações anteriores sobre o que deve ser aperfeiçoado no PIBID um maior estreitamento na relação entre IES e a escola conveniada e um aumento no número de horas dos bolsistas nas escolas parceiras.

O fortalecimento da relação já existente entre universidade e escola irá oportunizar ainda mais as trocas de conhecimentos entre essas instituições. Além disso, os estudantes das escolas conveniadas ao programa poderiam realizar mais visitas às instalações da IES para que estes a conheçam melhor e tenham um contato maior com a sua realidade, estimulando-os a ingressar em um curso de nível superior.

Em relação ao tempo disponibilizado para que os bolsistas estejam presentes nas escolas, um aumento das horas de participação desses discentes nessas instituições de ensino iria proporcionar maior convívio com os alunos, professores e grupo gestor da escola e esses licenciandos teriam também um maior tempo de convívio com o supervisor.

Gomes e Amorim (2016) afirmam que deve ocorrer, além de uma maior interação por parte dos bolsistas do PIBID, um maior envolvimento da escola conveniada, pois na relação entre bolsistas e alunos da educação básica, ambos possuem papéis relevantes um em relação ao outro em se tratando de formação na qual se podem obter importantes conhecimentos que vão além daque- les estudados em sala de aula.

\section{Considerações finais}

Ao final deste trabalho pode-se destacar que muitos licenciandos entrevistados afirmaram que as ações do PIBID possibilitam o confronto entre a teoria e a prática dos conhecimentos adquiridos no ambiente acadêmico de modo corriqueiro, possibilitando aos mesmos formar conclusões a respeito da aplicabilidade de conhecimentos teóricos no ambiente escolar. Consequentemente, acredita-se que esse bolsista perceberá a relevância da integração entre teoria e prática para sua formação e que através dessa relação também são estabelecidos novos saberes.

Sobre a alteração da perspectiva referente à docência e a realidade escolar, a maior parte dos licenciandos mencionou que as vivências oportunizadas pelo PIBID sempre ocasionam essa modificação em seu ponto de vista, pois como eles estão inseridos no espaço escolar agora não mais como estudante e sim como professor, os mesmos passam a perceber a escola de maneira geral com outros olhos e consequentemente, passam a compreender melhor a profissão em destaque, as situações presentes em seu cotidiano e sua relevância social. Essa mudança de visão sobre a realidade pode ser proveitosa já que o futuro professor compreendendo melhor o fun- 
cionamento da estrutura escolar pode encontrar o caminho para o ensino mais facilmente.

No que se refere às contribuições do PIBID para a formação docente dos licenciandos/bolsistas, uma quantidade significativa desses discentes declarou que esse programa sempre contribui nesse aspecto apontando que é proporcionado a esses bolsistas o contato com as situações reais da profissão docente e o seu cotidiano preparando-os melhor para a carreira do magistério.

Sobre o principal diferencial do licenciando que foi bolsista do PIBID em comparação ao discente que não participou do programa, estes enfatizaram tanto a questão das experiências adquiridas com o programa em questão, auxiliando em sua preparação para a carreira docente quanto o aperfeiçoamento da suas metodologias de ensino.

No que diz respeito aos impactos do PIBID para os seus supervisores, a maior parte desses professores relataram que as trocas de conhecimentos e experiências existentes entre bolsista-supervisor sempre os motivam a buscar novas informações e práticas metodológicas com o propósito de tornar o ensino mais dinâmico e atrativo, renovando os seus saberes e as metodologias já utilizadas por eles, aperfeiçoando sua prática pedagógica e, por conseguinte, interferindo positivamente no ensino e aprendizagem dos estudantes.

Em relação às contribuições do seguinte programa para sua formação continuada, a maioria dos supervisores afirmou que o PIBID sempre colabora nesse sentido sendo enfatizado em suas respostas que os bolsistas apoiam e incentivam os mesmos a dar continuidade em sua formação e até mesmo estimulando-os a ingressar em cursos de pós-graduação. Muitas vezes esse contato com professores mais experientes traz a tona a realidade do inacabamento sobre a formação. Deve-se sempre lembrar que é parte essencial da prática docente o constante aperfeiçoamento e que este deve perdurar até o fim da carreira de um determinado professor.

O PIBID permite que os licenciandos possam ter um contato direto com o contexto escolar e muitas vezes essa proximidade acontece antes mesmo de cursar as disciplinas de estágio supervisionado permitindo que esse discente possa desde o início de sua graduação vivenciar experiências que enriquecem sua formação enquanto docente.

Ao seguir a carreira do magistério, os discentes que atuaram no programa como bolsistas se sentem mais preparados e seguros por terem vivenciado situações pertencentes à profissão e, dessa forma, essas experiências adquiridas darão base para a sua ação pedagógica e maior confiança para a sua atuação profissional.

Os resultados obtidos demonstram que as contribuições desse programa são reais não somente para os licenciandos da amostragem em estudo, como também para os supervisores em relação ao aprimoramento dos seus conhecimentos profissionais. Essa pesquisa somente enaltece o sucesso do PIBID que envolve inúmeros discentes e docentes em todo o país, confirmando suas grandes contribuições principalmente para os professores em formação.

\section{REFERÊNCIAS}

BACCON, A. L. P.; BRANDT, C. F.; WOLSKI, D. T. R. M. Políticas públicas de formação de professores: a construção de saberes docente na formação inicial e continuada em serviço no contexto pibid. In: ANAIS...

XXVI SIMPÓSIO BRASILEIRO DE POLÍTICA E ADMINISTRAÇÃO DA EDUCAÇÃO. Recife, 2013. v. 26.

BERTOLDO, J. V.; CHIAPINOTO, A. M. As contribuições do pibid para a formação de professores para a educação básica. Thaumazein: Revista Online de Filosofia, v. 7, n. 14, p. 20-27, 2014.

BRASIL. PIBID - Programa Institucional de Bolsa de Iniciação à Docência. 2017. Disponível em: <http: //www.capes.gov.br/educacao-basica/capespibid> Acesso em: 20 fev. 2017.

DICK, A. P.; DIESEL, D.; HORN, D. Pibid: Uma política pública para potencializar a articulação entre teoria, prática e reflexão docente. Revista Caderno Pedagógico, v. 12, n. 2, p. 138-148, 2015.

FELÍCIO, H. M. d. S. O pibid como "terceiro espaço" de formação inicial de professores. Revista Diálogo Educacional, Pontifícia Universidade Católica do Paraná, v. 14, n. 42, p. 415-434, 2014.

GAMA, A.; JÚNIOR, E.; BARBOSA, E.; NETO, F.; TARGINO, K.; SOUZA, M.; FERNANDES, P. A importância do projeto pibid na formação dos alunos de licenciatura em química do ifrn campus-apodi. In: ANAIS DO IX CONGIC. IX Congresso de Iniciação Científica do IFRN. Currais Novos, 2013. v. 9, p. 1519-1525.

GIL, A. C. Como elaborar projetos de pesquisa. 4. ed. São Paulo: Atlas, 2009.

GOMES, M. P.; AMORIM, B. A. A importância do pibid para a iniciação a docência na unifebe e as 
CONTRIBUIÇÕES DO PIBID PARA A FORMAÇÃO INICIAL DOCENTE EM LICENCIATURA EM QUÍMICA: UM OLHAR ATENTO SOBRE OS FUTUROS PROFESSORES.

contribuições para a educação básica de brusque e região. Cadernos do PIBID, v. 1, n. 2, p. 10-19, 2016.

HERBER, J.; FILHO, W. A. S.; PINO, J. C. D. Avaliação do pibid/subprojeto-química a partir da análise das atividades desenvolvidas nas escolas parceiras nos anos de 2014 e 2015. In: ANAIS... ENCONTRO NACIONAL DE ENSINO DE QUÍMICA. Florianópolis, 2016. v. 18.

JARDILINO, J. R. L.; OLIVERI, A. M. R. A formação continuada de professores no âmbito do pibid na região dos inconfidentes (mg). EntreVer-Revista das Licenciaturas, v. 3, n. 4, p. 237-249, 2013.

MARQUES, B.; CORDEIRO, M.; TAVARES, V. As contribuições do pibid para a formação docente: Um relato da vivência de bolsistas do pibid letras/arapiraca. In: ANAIS... Congresso de Inovação Pedagógica em Arapiraca. Arapiraca, 2015. v. 1, n. 1, p. 1-8.

MARTINS, M. M. M. d. C.; NETA, M. D. L. d. S.; LEITE, R. C. M. O pibid e a melhoria na formação contínua de professores no ceará. In: JUNQUEIRA\&MARIN (Ed.). Encontro Nacional de Didática e Práticas de Ensino. Campinas, 2012. v. 16, p. 3560-3571.

MATOS, G. S. O PIBID no processo de formação continuada dos professores supervisores de Educação Física: aspectos de uma política curricular. Dissertação (Mestrado em Educação) Faculdade em Educação, Universidade Federal do Rio de Janeiro, Rio de Janeiro, 2016.

MATTANA, S. D.; ZACOVELLO, R.; THEISEN, G. R.; MORESCO, T. R.; GARLET, T. M. B.

Contribuições do pibid na formação inicial: intersecções com os pontos de vista de licenciandos de biologia. Revista Eletrônica em Gestão, Educação e Tecnologia Ambiental, v. 18, n. 3, p. 1059-1071, set./dez 2014.

NEITZEL, A. A.; FERREIRA, V. S.; COSTA, D. Os impactos do pibid nas licenciaturas e na educação básica//the impacts of pibid in licensure and in basic education. CONJECTURA: filosofia e educação, v. 18, n. Edição Especial, p. 98-121, 2013.

PERETTO, E.; POTRICH, M.; LOZANO, E. R.; BOGONI, R. F.; EICHELBERGER, A. C. A. Influência do pibid nas aulas de ciências e biologia. Unoesc \& Ciência-ACHS, v. 6, n. 2, p. 181-186, jul./dez. 2015.
ROSA, K. S.; MATTOS, L. Tem gente nova na escola: os benefícios do pibid para o espaço escolar. Veras, v. 3 , n. 2 , p. $160-173$, jul./dez. 2013.

SANTOS, R. S.; NASCIMENTO, V. R. d.; SANTOS, D. G. d.; URATA, T. D. C.; NUNES, S. M. T. Pesquisa ação: acompanhando os impactos do pibid na formação docente. In: ANAIS... CONGRESSO DE PESQUISA, ENSINO E EXTENSÃO. Samanbaia, 2011. v. 8.

SILVA, F. R. d. O pibid no contexto políticas públicas para a formação de professores no brasil. In: ANAIS.. CONGRESSO DE EDUCAÇÃO DA GRANDE DOURADOS. Grande Dourados, 2016. v. 2, p. 1-14.

SILVA, M. M.; SILVA, G. d. O.; FLÔR, P. R. C.; LIMA, S. V.; FALCÃO ${ }^{1}$, A. P. Contribuições do pibid no processo de formação inicial de licenciandos em química do ifpe-campus vitória de santo antão. In: ANAIS... SIMPÓSIO NACIONAL DE ENSINO DE CIÊNCIA E TECNOLOGIA. Ponta Grossa, 2014. v. 4.

SOPELSA, O.; BALDISSERA, D.; MELLO, R. O. A articulação entre a educação superior e o pibid na formação continuada de professores. In: ANAIS... ANPED SUL. Curitiba, 2016. v. 11, p. 1-16.

SOUSA, Y. K. D.; AFONSO, L. P. R.; Sá, R. A. Uma experiência no estágio supervisionado utilizando metodologias diferenciadas no ensino-aprendizagem do conteúdo de "sistema, substância pura e mistura". In: ANAIS... CONGRESSO NACIONAL DE EDUCAÇÃO. Campina Grande, 2015. v. 2.

TOBALDINI, B. G. Implicações do pibid para a formação inicial e continuada de professores de química. In: JUNQUEIRA\&MARIN (Ed.). ENCONTRO NACIONAL DE DIDÁTICA E PRÁTICAS DE ENSINO. Campinas, 2012. v. 16, p. 5211-5222.

ZEULLI, E.; BORGES, M. C.; ALVES, V. A.; JÚNIOR, A. P. O. O pibid e a formação inicial dos professores da uftm: diferentes experiências entre seus atores. In: JUNQUEIRA\&MARIN (Ed.). ENCONTRO NACIONAL DE DIDÁTICA E PRÁTICAS DE ENSINO. Campinas, 2012. v. 16, p. 2690-2702. 